\title{
Childhood Cancer in Africa: Past, Present, and Future
}

\section{Cancer de l'enfant en Afrique : passé, présent et futur}

\author{
D.C. Stefan \\ C) Springer-Verlag France 2014
}

\begin{abstract}
Africa is a young continent where children represent $41 \%$ of the total population, a proportion much higher than in the rest of the world. With appropriate health and education, the African youth has the potential to generate an unparalleled economic growth. However, the health of many young Africans is too often endangered by poor nutrition or infectious diseases like malaria and tuberculosis. Compared with these threats, pediatric cancer appears to play a minor role, given that its incidence is estimated at 94 cases/million [1] or around $40000-50000$ new cases per year for the whole continent. Consequently, it remains a low priority on the health agenda for many African governments. Beyond all that can be said about neglect of human rights, not allocating sufficient resources to pediatric oncology is also economically short-sighted, as childhood cancer is highly curable and up to $80 \%$ of the treated children will attain adulthood and be productive.
\end{abstract}

\section{Past}

Contrary to most malignant diseases in adults, pediatric cancer is less associated with environmental or lifestyle factors, but rather with genetic abnormalities. Therefore, it is almost not preventable. In the past the survival rate of childhood cancer was very low if existed at all.

Childhood cancer in the past was often not recognized as an entity, being mainly confused with infectious disease. Human immunodeficiency virus was not yet discovered and the African pediatric oncology was dominated by the lymphomas.

Denis Burkitt played an essential role in describing for the first time in 1957, in Uganda, the disease which is known today as the Burkitt lymphoma together with the distribution along the African belt.

D.C. Stefan $(\bowtie)$

Department of paediatrics and child health, Tygerberg Hospital and Stellenbosch

e-mail : cs@sun.ac.za

\section{Present}

Unlike developed countries, lymphomas, nephroblastoma, Kaposi sarcoma, and retinoblastoma are the most common pediatric tumors in Africa [2].

Children with cancer should be treated in dedicated units. While the number of existent pediatric oncology units across Africa is not precisely known, a recent survey of 38 units spread on the continent indicated that at least a dedicated ward for children with malignant disease existed in 24 of the institutions [3].

There are no statistics indicating how many pediatric oncologists are active in Africa or how many nurses have been specially trained in pediatric cancer care. Such specialist cadres are mostly found in Northern Africa and in South Africa, while in many other countries on the continent the children would be treated by general oncologists, general pediatricians or even radiotherapy doctors [3]. The task of the few specialists and nurses involved in caring for children with cancer is made even more difficult by the soaring numbers of Kaposi sarcomas and Burkitt lymphomas associated with HIV infection.

An important improvement in the outcome of children treated for cancer in Africa was brought about by the various forms of international collaboration, out of which the most well-known is the Franco-African Group for Paediatric Oncology (FAGPO). The non-African partners contributed to train personnel, to develop infrastructure and research capability and sourced a large fraction of the funds required to implement such objectives. Major scientific organizations like the International Society of Paediatric Oncology (ISPO) and African Organization for Research and Training in Cancer (AORTIC) are now active in Africa, contributing to raise the professional standard of their members. Last, but not least, the number of parent organizations is increasing. Their role - in providing funds for medicine, transport, shelter for the children and their families during the treatment, as well as psychological support-is invaluable for the success of therapy. 
In spite of all these positive developments, the survival rates remain low in Africa with reports between $20-40 \%$ in many centers in severe contrast with the survival rates as high as $80 \%$ which have been reported from resource-rich countries [4].

Main challenges encountered in caring for children with cancer in Africa are related to lack of education and training of the health professionals, lack of cytostatics and free availability of drugs and investigations, delayed diagnosis and lack of awareness of the population, and the inadequacy of interest of the governments and policy makers in the disease.

\section{Future}

Starting from the present status of pediatric oncology, the future of childhood cancer in Africa would require effective action in the following directions:

- The need for improved professional education: formation of an African School for Pediatric Hematology-Oncology should be founded.

- Cancer registries should be given priority by health authorities.

- A common curriculum in pediatric oncology across the continent should be agreed upon, to be introduced in all undergraduate pediatric programs of faculties of health.

- Twinning programs between African units and prominent overseas centers should be promoted.
- Palliation programs should be instituted in all African units.

- National Cancer Plans as envisaged by WHO should be developed by governments, including provisions for pediatric cancer care.

- Groups of interest in research on specific targets should be developed: cost effectiveness, palliation, supportive care, adapted treatment protocols, striving to provide specific African solutions.

Conflict of interest D.C. Stefan declare not to have any conflict of interest.

\section{References}

1. Ferlay J, Shin HR, Bray F, et al (2008) GLOBOCAN 2008 v2.0, Cancer Incidence and Mortality Worldwide: IARC CancerBase $\mathrm{n}^{\mathrm{o}} 10$ [Internet]. Lyon, France: International Agency for Research on Cancer 2010. Available from: http://globocan.iarc.fr, accessed on $11 / 07 / 2013$

2. Stefan DC (2012) Distribution of childhood cancer in Sub Saharan Africa. The 34th International Association of Cancer Registries, 17-19 September 2012, Cork Ireland - abstract

3. Stefan DC (2014) Childhood Cancer in Africa: An Overview of Resources. J Pediatr Hematol Oncol 2014 Jan 30. [Epub ahead of print]

4. Gatta G, Capocaccia R, Stiller C, et al (2005) Childhood cancer survival trends in Europe: a EUROCARE Working Group study. $\mathrm{J}$ Clin Oncol 23:3742-51 